\title{
Strategies to Avoid Corruptions in FIFA
}

\author{
Guoying Yuan, Houzhong Jin, Hongquan Li and Si Liu \\ Sports Economics and Management School, Central University of Finance and Economics \\ Beijing 100081, China \\ E-mail: jinhouzhong@126.com
}

Chuanchuan Kong and Li Lin

Beijing Sport University, Beijing 100084, China

E-mail:kcc139@163.com

Received: March 11, 2011 Accepted: April 22, $2011 \quad$ doi:10.5539/ijbm.v6n6p215

\begin{abstract}
By the method of literature and documentation, the causes of the frequent corruptions in FIFA (Federation International de Football Association) and relative strategies to avoid corruptions are analyzed and proposed in this article, and the research result can be used for references to solve this problem for relative organizations.

Keywords: FIFA, Corruption, Avoidance

FIFA was established at May 21, 1904 in Paris of France. At present, the competitions managed by FIFA mainly include World Cup, Olympic Football Game, FIFA World Youth Championship, and Women's World Cup. Though the initial property of FIFA was "non-profit organization", but in recent years, FIFA has frequently participated in various commercial activities, and obtained abundant profits. Since 2006, the year income of FIFA has been counted by hundreds of millions of dollars, for example, 0.749 billions of dollars in 2006, 0.882 billions of dollars in 2007, 0.957 billions of dollars in 2008, and 1.059 billions of dollars in 2009 (data from website of "http://www.fifa.com"). As the most profitable physical organization, FIFA which was the so-called "non-profit organization" should seriously treat the problem of corruption. The corruption problems and how to avoid these problems are studied as follows.
\end{abstract}

\section{Main corruptions}

In Nov of 2010, British media begun to expose the black curtain of FIFA, and pointed out that two members in FIFA Executive Committee were suspected to use right "selling votes". To patch up the quarrel, FIFA suspended 6 involved members from their duties. But a TV program made by BBC still exposed that there were another three heavy-level official in FIFA received bride and sold their votes. In fact, from early 1989 to 1999, ISL Company continually bribed three members of FIFA Executive Committee, and secretly used 175 sums of money, and the total amount achieved 0.1 billion dollars. Furthermore, someone doubted the fairness that FIFA drew lots for competition. Many people thought that the temperatures of lot balls were different, because many lot drawers including the president of UEFA always selected the ball through many times of comparison. FIFA manipulated the competitions of World Cup to achieve the maximum profit was the focus concerned by the public, and which was again embodied in the group game of Portugal and Brazil in the World Cup of 2010. Not only that, some members of FIFA Executive Committee resold the entrance tickets of World Cup at a profit. Actually, there were many corruption problems in FIFA, and only in 2010, the bribe scandal for the World Cup bidding, and the dirty trade of selling votes, and the financial corruption case in Switzerland exposed by British media consecutively troubled FIFA.

\section{Causes}

\subsection{Overlarge powers of FIFA}

Since 1970s, the professional sports have been developed unprecedentedly, and huge amounts of investment have been attracted in this industry, and the production value created by the sports industry has increased largely. Vast TV revenues and sponsorships have created higher profit. As the first biggest sport in the world, football is incomparable in the professionalization and concern degree than other sporting events and sports organizations. 
In so much football competitions, the international influence of World Cup is undisputed. Under this situation, to strive for the hosting right, some countries will use unconventional even illegal measures, which is one of objective factors to produce corruption.

\subsection{Lacking in external supervisions}

FIFA was established in 1904 as a civil non-profit organization, which made it could avoid almost all supervisions and controls. As an international sports organization, FIFA must depend on local judicial department of the place of the headquarters. The headquarters of FIFA is in the Zurich of Switzerland. According to the reports of The Times, the sports minister of Switzerland, Manuel organized the investigation team by himself, and would thoroughly investigate the "bribery vote" of FIFA. But this investigation was still very difficult. In Switzerland Laws, non-profit organizations are not applicable for the crime of corruption (Zhi, 2010). FIFA is just such an "international sports organization". International sports organizations do not belong any one country, and the performing of its function and power could not be controlled, which will certainly breed interior corruption in this organization.

\subsection{Too simple selection for the places of large-scale competitions}

For large-scale sports competitions such as World Cup, the selection of hosting place is decided by the votes from members of FIFA Executive Committee, which would obviously further expand the power of FIFA with excessively inflated power. Simple selection process has not only provided more convenient soil of corruption, but increased quite big difficulty for the investigation after corruption. In the voting process, the difference among various application countries was not obvious, so the members of FIFA Executive Committee had all reasons to argue in favor of their votes, and only the bribed party or the bribing party would possess powerful evidence, which is one of causes that FIFA still is un-apprehended through many years' criticize.

\subsection{Insiders' ability of self-discipline should be further enhanced}

In recent years, the annual income of FIFA is above 1 billion dollars, and the amount of aligned countries even exceeded the amount of UN, but how to realize effectively interior control and restriction for such a big sports organization? Before 2006, it is impossible. In 2006, FIFA established the morality committee. Even so, the interior supervision and restriction are only possible in paper and program. In addition, some members in FIFA Executive Committee could not cognize the illegal behaviors enough, and they have not realized the bad influences of their mistakes for the development of the football sports, and in the exterior corruption, the corruption occurs very easily. If things continue this way, the corruption in FIFA is inevitable.

\section{Strategies to avoid corruptions}

\subsection{Quickening the legislation step}

According to relative reports, some local institutions served for the World Cup in South Africa had prepared to accuse FIFA, because the debts owned by FIFA in the World Cup have not been paid up to now. In fact, the examples that FIFA defeated in the suit of economic disputes are very rare. In the day that the professional football quickly developed, for the "non-profit organization" with large profit such as FIFA, relative judicial departments should quicken the legislation to eliminate its coat of "non-profit organization" and publicize its finance, which could really avoid the leak that FIFA utilizes policies.

\subsection{Local judicial departments should strengthen the supervision for the branches}

Because FIFA is independent of countries, and most of its branches are located in different countries. Therefore, the local judicial departments should undertake corresponding responsibilities, and should not shield FIFA's illegal behaviors because of various reasons such as development economy and enhancing reputation. In recent tens of years, professional football has been developed quickly, attracting a large number of sponsors, and largely promoting the development of relative service industries and neighboring industries. For local economic development, some countries and regions will provide many preferential policies for the organizations of professional football, and these policies will not only promote the development of this sports event, but also induce many illegal behaviors for professional football organizations. Therefore, the local judicial department where the sports organization is located at is the most direct and strong power to restrain corruption.

\subsection{Establishing the supervision institution in the international range}

The deficiency of supervision is the essential cause of the corruption in FIFA. Therefore, the supervision institutions should be established in the world range tentatively. In the supervision process, on the one hand, the supervision institution should have the power to check the interior financial state of FIFA, and investigate suspected officials. The supervision institution should have its own independent auditing institution, and 
establish its own reasonable auditing system, and ensure that the interior financial state is opening and clear. On the other hand, the sponsor enterprise and local governments which have the relationship with FIFA should be the supervision objects, which should be supported by local governments of various countries.

\subsection{Strengthening interior management system}

Except for exterior supervision mechanism, the interior management system reform is also very important. After Salt Lake Scandal, the president of International Olympic Committee (IOC) President at that time, Samaranch performed a series of reform. In this reform, IOC would not allow committee members visited candidate cities, and only the hosting delegation of IOC can investigate candidate cities and the process of bidding the IOC became more transparent and standard. Even the Olympic Character had been modified after this event, and the Olympic Morality Committee was established to specially supervise the IOC interiorly. The courage and dimension of Samaranch's reform was unprecedented, and this reform successfully saved IOC, and this reform had not stricken the development ability of IOC. After that, the countries which successfully hosted the IOC or the Olympic Winter Games were all clear, without any "bribe vote" scandal. To walk away from the present shadow, FIFA should use the reform of IOC for reference.

\subsection{Standardizing the process of various selections and evaluations}

The voting process of FIFA has been the focus for a long time. It is not reasonable for the big event of hosting the World Cup which is decided by only several of executive members. FIFA should establish special investigation team to comprehensively evaluate the infrastructures and human \& geographic environment, and make the hosting competition more fairly. The lot drawing of World Cup is another flaw leaved for the public by FIFA. The lot drawing process is completely accomplished manually, whether it is designed in advance? FIFA could not standardize the voting process slowly, and people have lost trust for it. The standard and ordered voting process is to respect the competition and those sports fans who pay close attention to this game.

\section{Conclusions}

FIFA in the teeth of the storm must take out coverage and match relative organizations to quicken the legislation step, establish the supervision institutions in the whole world, standardize the process of various votes, strengthen the supervision of its branches and the construction of interior management system, reform those harmful systems, and clear its interior corruptions. Only in this way, the public support for FIFA can be saved, and the first biggest sports event can be developed continually and stably.

\section{References}

Ren, Hai. (2001). Discussion on Organizational Reform of IOC after Bidding Scandal Exposure in Salt Lake City. Journal of Beijing Sport University, No. 24(1), P. 1-4.

Xin, Xidong \& Shi, Youkuan. (2003). On Corruption in Competition and Its Controlling Methods. Journal of Anhui Sports Science, No. 24(3), P. 8-15.

Zhao, Jinling. (2010). Study of Sports Corruption within an Economic Framework: Based on the Theory of Rent-seeking. Journal of Physical Education Institute of Shanxi Normal University, No. 25(1), P. 16-18.

Zhi, Ran. (2010). The Switzerland Government Registered and Investigated the Scandal of Selection Bribery, and the FIFA will Face Heavy Punishment. [Online] Available: http://sports.qq.com/a/20101126/001359.htm (Nov 26, 2010). 